\title{
EARLY LAPAROSCOPIC APPENDICECTOMY IN MANAGEMENT OF APPENDICEAL MASS
}

\author{
S. Shyamchand Singh¹, NG. Javan², Khumallambam Ibomcha Singh³, Tozo Luwang 4
}

${ }^{1}$ Assistant Professor, Department of Surgery, Jawaharlal Nehru Institute of Medical Sciences, Porompat, Imphal, Manipur. ${ }^{2}$ Associate Professor, Department of Surgery, Jawaharlal Nehru Institute of Medical Sciences, Porompat, Imphal, Manipur. ${ }^{3}$ Assistant Professor, Department of Surgery, Jawaharlal Nehru Institute of Medical Sciences, Porompat, Imphal, Manipur. ${ }^{4}$ Senior Resident, Department of Surgery, Jawaharlal Nehru Institute of Medical Sciences, Porompat, Imphal, Manipur.

\section{ABSTRACT}

\section{BACKGROUND}

Acute appendicitis is a most common surgical emergency. Approximately, $10 \%$ of acute appendicitis patients present with appendiceal mass. Surgical management of appendiceal mass remains controversial. Majority of surgeons preferred conservative treatment. This study was carried out to evaluate our experience in early laparoscopic appendicectomy (LA) in the management of appendiceal mass.

\section{MATERIALS AND METHODS}

For the study, a total of 48 patients who were admitted with a diagnosis of appendiceal mass in the Department of Surgery during the period from July 2015 to December 2016 were included. The selection of the patients was done on the basis of the clinical history, clinical examination, laboratory tests and radiological findings. All 48 patients who were diagnosed with appendiceal mass underwent laparoscopic appendicectomy.

\section{RESULTS}

Laparoscopic appendicectomy was attempted in all 48 patients. There were 32 males and 16 females within age range of 10 to 80 years, maximum in 30 - 50 years age group. One case was converted to open and segmental colectomy was performed due to dense adhesion with unhealthy base and gangrenous caecal wall. The base of the appendix was sutured in 7 cases and drain was left in for 3 - 4 days. Endoloop was used in remaining 40 cases. There was difficulty in localisation of appendix and bleeding was noted in 4 cases during intraoperative period. The average operative time was 80 minutes (range from 30 to 120 minutes) and average postoperative hospital stay was 4 - 5 days (Range from 2 to 7 days). Except for mild fever which occurred in four patients, no major postoperative complications were seen.

\section{CONCLUSION}

Early laparoscopic appendicectomy during the index admission of patient with an appendiceal mass is feasible and safe. It also avoids the need for a second admission and misdiagnosis.

\section{KEYWORDS}

Laparoscopic Appendicectomy, Perforation, Appendicitis.

HOW TO CITE THIS ARTICLE: Singh SS, Javan NG, Singh KI, et al. Early laparoscopic appendicectomy in management of appendiceal mass. J. Evolution Med. Dent. Sci. 2017;6(59):4367-4371, DOI: 10.14260/Jemds/2017/944

\section{BACKGROUND}

Acute appendicitis remains the most common intraabdominal surgical pathology requiring surgical intervention. The patients presenting late in the course of acute appendicitis are complicated by the development of an inflammatory mass in the right iliac fossa. ${ }^{1}$ An appendiceal mass is the end result of a walled-off appendiceal perforation and represents a pathological spectrum ranging from phlegmon to abscess. ${ }^{2.3}$ It is encountered in $2 \%-6 \%$ of patients presenting with acute appendicitis. ${ }^{2,3,4}$ The treatment of appendiceal mass is controversial; however, there are several management options for appendiceal mass. 1,3,5,6 Traditionally, appendiceal mass was treated by

Financial or Other, Competing Interest: None.

Submission 18-06-2017, Peer Review 13-07-2017,

Acceptance 18-07-2017, Published 24-07-2017.

Corresponding Author:

Dr. NG. Javan,

Associate Professor, Department of Surgery,

Jawaharlal Nehru Institute of Medical Sciences,

Porompat, Imphal East, Manipur-795005.

E-mail:ngjavan@yahoo.co.uk

DOI: $10.14260 /$ jemds $/ 2017 / 944$

\section{(c) $(i) \$$}

conservative method followed by interval appendicectomy 4 to 6 weeks later believing that any attempt to remove appendix is hazardous, time consuming and may lead to life threatening complications such as faecal fistula. ${ }^{7}$ It is now changing from the traditional approach of initial conservative treatment followed by interval appendectomy to immediate appendectomy.8,9 However, this change is not widely accepted and a large number of surgeons still continue to adopt the same traditional conservative approach. ${ }^{10}$

In $10-20 \%$ of the cases, conservative management fails and the patients need an emergency operation due to peritonitis, which is comparatively more difficult and carries more morbidity and mortality. ${ }^{11,12}$ In addition, the patient may suffer a recurrence of appendicitis after being discharged from the hospital.13,14

Early surgical intervention has been known to be an effective alternative to conservative therapy for a long time, as it considerably reduces the total hospital stay and obviates the need for a second admission. ${ }^{15}$ The early operation on the other hand has an edge of being curative in the index admission and ensures early return to work and higher compliance. Controversy is not only confined to management, but is also about the technique, laparoscopy versus open. For 
decades, open appendectomy has been the standard treatment for all forms of appendicitis. ${ }^{16,17}$

Since its description in the early 1980s, laparoscopic appendicectomy has become an acceptable approach for simple appendicitis. ${ }^{18,19,20}$

However, the role of laparoscopy in the treatment of complicated appendicitis is controversial. With the advances in laparoscopic instrumentation and technical skill it is possible to remove an inflamed appendix in presence of mass successfully. The aim of this study is to evaluate the feasibility and safety of early laparoscopic appendicectomy in the management of appendiceal mass.

\section{MATERIALS AND METHODS}

The present case series study of early laparoscopic appendicectomy in management of appendiceal mass has been carried out in the Department of Surgery, Jawaharlal Nehru Institute of Medical Sciences (JNIMS), Imphal, Manipur. The approval of medical ethics was taken from Medical Ethics committee of JNIMS. Informed consent was taken from patients for this study.

A total of 48 patients who presented with acute appendicitis with appendiceal mass were studied during 11/2- year period from July 2015 to December 2016 in our hospital. Preoperatively appendiceal mass was diagnosed by clinical examination and ultrasound of the whole abdomen and confirmed by intraoperative finding. All clinical, investigation and operative findings were recorded into a database. Collected data included gender, age, clinical features, investigations, intra-operative findings, operative time, postoperative complications and hospital stay. Laparoscopic appendicectomy was performed in all patients within 24 hours of admission. Laparoscopic appendicectomy was attempted in all patients by using three-port technique. Endoscopic pre-tied loops were used for ligation of the base of appendix. All area of the intra-abdominal collection was aspirated and peritoneal cavity was washed thoroughly with normal saline. All patients were given aerobic and anaerobic antibiotics coverage. An abdominal drain was kept in patients in whom we feel it is required. Conversion of laparoscopic surgery to open laparotomy was done in difficult situations. The feasibility of laparoscopic appendicectomy in appendiceal mass was assessed on the basis of ability to complete the surgery by laparoscopic method.

\section{RESULTS}

The age at presentation in the present study is as shown below-

\begin{tabular}{|c|c|c|}
\hline Age Group & No. of Cases & Percentage \\
\hline 10 to $<30$ Years & 14 & $29.16 \%$ \\
\hline 30 to $<50$ Years & 20 & $41.66 \%$ \\
\hline 50 to $<70$ Years & 11 & $22.91 \%$ \\
\hline 70 to $<90$ Years & 3 & $6.25 \%$ \\
\hline \multicolumn{2}{|c|}{ Table 1. Age Distribution of Patients } \\
\hline
\end{tabular}

During 1-1/2 years study period, 48 patients (32 males and 16 females) underwent laparoscopic appendicectomy for appendiceal mass. Male to female ratio was 2:1. The maximum number of patients was seen in age group 30-50 years.

\begin{tabular}{|c|c|c|}
\hline $\begin{array}{c}\text { Clinical } \\
\text { Presentation }\end{array}$ & $\begin{array}{c}\text { Number of } \\
\text { Patients }\end{array}$ & Percentage \\
\hline Right Iliac fossa pain & 41 & $85.41 \%$ \\
\hline Generalised abdominal pain & 7 & $14.58 \%$ \\
\hline Fever & 30 & $62.5 \%$ \\
\hline Nausea & 35 & $72.91 \%$ \\
\hline Vomiting & 15 & $31.25 \%$ \\
\hline Diarrhoea & 5 & $10.41 \%$ \\
\hline Loss of appetite & 25 & $52.08 \%$ \\
\hline Right iliac fossa mass & 45 & $93.75 \%$ \\
\hline Abdominal guarding & 5 & $10.41 \%$ \\
\hline \multicolumn{2}{|c|}{ Table 2. Clinical Features } \\
\hline
\end{tabular}

The duration of treatment elsewhere before admission ranges from three to ten days. In our study, 45 patients (85.41\%) presented with right iliac fossa pain and 7 patients (14.58\%) presented with generalised abdominal pain. Thirty patients $(62.5 \%)$ had fever and 35 patients $(72.91 \%)$ had nausea. Most of the patients were found to have tenderness with palpable mass in right iliac fossa (93.75\%). On Investigation, 39 patients $(81.25 \%)$ had leucocytosis of more than $12,000 / \mathrm{mm}^{3}$. Ultrasound can demonstrate the presence of appendiceal lump in 35 patients and the remaining 13 patients were identified during laparoscopy.

Laparoscopic appendicectomy was performed in all patients within 24 hours of admission. In one patient, there was difficulty in localisation of appendix due to dense adhesion with unhealthy appendiceal base with gangrenous caecal wall and so was converted to open segmental colectomy which was excluded from the study. In 7 patients, bases were sutured with Vicryl 2-0 and abdominal drain was left in for 3-4 days. In remaining 40 patients, endoscopic pretied loops were used for ligation of the base of appendix and no drain was kept. Since we were able to operate in all cases and finish the surgery laparoscopically, it is feasible to do a laparoscopic appendicectomy in patients with appendiceal mass.

Operative finding, operative time, complication and hospital stay are shown in tables below.

\begin{tabular}{|c|c|}
\hline Operative Findings & Number of Patients \\
\hline Simple Mass (Phlegmon) & 34 \\
\hline Loculated pus collection & 8 \\
\hline Appendiceal Abscess & 5 \\
\hline Dense Adhesion & 1 \\
\hline
\end{tabular}

The commonest intra-operative findings in our study was simple appendiceal mass (phlegmon) which was seen in 34 cases.

\begin{tabular}{|c|c|}
\hline Operative Finding of Appendix & Number of Cases \\
\hline $\begin{array}{c}\text { Inflamed appendix without } \\
\text { gangrene and perforation }\end{array}$ & 33 \\
\hline Gangrene with perforation & 8 \\
\hline Gangrene without perforation & 7 \\
\hline \multicolumn{2}{|c|}{ Table 4. Intraoperative Finding of Appendix } \\
\hline
\end{tabular}

The most common intra-operative finding of appendix was inflamed appendix without gangrene and perforation seen in 33 cases. 


\begin{tabular}{|c|c|}
\hline Operation Time (Minutes) & Number of Patients \\
\hline $30-60$ & 15 \\
\hline $60-90$ & 25 \\
\hline $90-120$ & 7 \\
\hline \multicolumn{2}{|c|}{ Table 5. Operation Times } \\
\hline
\end{tabular}

The operative time ranges from 30 to 120 minutes with an average of 80 minutes.

\begin{tabular}{|c|c|}
\hline Type of Complication & Number of Patients \\
\hline Intra-operative Bleeding & 4 \\
\hline Post-operative Fever & 4 \\
\hline \multicolumn{2}{|c|}{ Table 6. Complications } \\
\hline
\end{tabular}

There was intraoperative bleeding in 4 cases which was controlled by harmonic scalpel, mild oozing by pressure. Except for mild fever in four patients, there were no major post-operative complications seen in our study.

\begin{tabular}{|c|c|}
\hline Hospital Stay (Days) & Number of Patients \\
\hline $2-3$ & 10 \\
\hline $4-5$ & 30 \\
\hline $6-7$ & 7 \\
\hline \multicolumn{2}{|c|}{ Table 7. Hospital Stay } \\
\hline
\end{tabular}

The average hospital stay was 4 - 5 days.

\section{DISCUSSION}

There are many controversies regarding management of appendiceal mass. Traditional treatment of appendiceal mass is conservative, which is followed by interval appendicectomy.6,8 Most surgeons do not widely accept early surgical intervention for appendiceal mass but continue to adopt same traditional conservative approach. ${ }^{9}$ Recently, laparoscopic approach has been extended to all kind of complicated appendicitis.

The role of laparoscopic appendicectomy for appendiceal mass has been added to the list of controversies. The earlier belief was that surgery is difficult in a state where the inflamed appendix is buried deep in the mass and the bowel loops are friable. However, this is no more a valid argument at present, due to an improvement in anaesthesia, electrosurgical unit and antibiotics. The operative problems such as localisation of the appendix, adhesiolysis and bleeding can be tackled with a magnified view of the laparoscope. LA provides the advantages of panoramic view with increased magnification, ability to visualise the hidden corners and clearance of purulent material as compared to the open technique.

It is not always possible to distinguish between an appendiceal mass and an appendiceal abscess before the operation. And non-operative management is not always successful.21,22,23 In Thomas'21 series, six of 37 patients thought to have a phlegmon were subsequently found to have abscesses. In our study, 34 cases were of phlegmon, 8 cases were loculated pus collection and 5 patients were abscesses out of 48 patients diagnosed as appendiceal mass.

Jordan et al ${ }^{15}$ in 1979, performed 42 open appendicectomies in palpable masses and recommended early surgery in patients with appendicitis with palpable masses. Horwitz et $\mathrm{al}^{24}$ and others have suggested avoiding the laparoscopic approach in complicated appendicitis because of the increased risk of post-operative, intraabdominal abscesses. ${ }^{25,26}$ None of our patients developed such complications as good peritoneal lavage with a large amount of normal saline was routinely done in our cases, in addition to intravenous and oral antibiotic regimens.

Valla et $\mathrm{al}^{27}$ recommended the open approach in cases with appendiceal masses. In contrary, our study and many other studies ${ }^{28,29}$ have showed that appendiceal masses can be successfully treated laparoscopically. Our findings matched favourably with others in terms of safety and feasibility.

Richards et $\mathrm{al}^{28}$ reported that laparoscopic appendicectomy resulted in fewer complications, a shorter hospital stay and a lower hospital cost than open appendectomy in patients with perforated appendicitis. Chin et $\mathrm{al}^{29}$ found laparoscopic appendicectomy feasible and safe for complicated appendicitis. Tirabassi et al ${ }^{30}$ reported a considerably high conversion rate (36\%) after laparoscopic operation for perforated appendicitis. In our series, conversion was done in only one case due to dense adhesion with unhealthy appendiceal base and gangrenous caecal wall.

There are several advantages of the laparoscopic approach in complicated appendicitis. It enables visualisation of the whole abdominal cavity and a thorough peritoneal lavage, which is difficult with a small incision. In open surgery, atypical localisation of the appendix or inaccurate diagnosis may require an extension of the incision as well. The laparoscopic approach also allows patients to become mobile and pain-free much faster, due to less trauma to the muscles and fascia. ${ }^{31}$ Another advantage of laparoscopy lies in a $30 \%$ lower rate of adhesions, which is particularly a common late complication, especially in children with perforated appendicitis. ${ }^{32}$

The benefit of a shorter hospital stay in laparoscopic appendicectomy was not observed in our series. This is mainly due to our policy of giving intravenous antibiotics for a longer period of about 4 to 5 days in our studies. The average length of stay with conservative treatment varied from 10 to 18 days $^{33,34}$ with a further eight days required for elective appendicectomy. Our patients had an average hospital stay of 4-5 days which is much shorter as compared with conservative treatment.

LA in complicated appendicitis has been reported to offer increased safety, shorter length of hospital stay, less pain and quicker return to normal activity with fewer complications. ${ }^{35,36,37,38}$ In contrast, it has also been reported that LA in complicated appendicitis is associated with higher risks of postoperative intra-abdominal abscess formation, bleeding and bowel injuries. ${ }^{39,40}$ In our study, only 4 patients had mild fever without any major complication. We feel that LA is safe, feasible and effective in complicated appendicitis. Early operation also has an edge of being curative in the index admission and ensures early return to work and higher compliance.

\section{Limitations}

One of the drawback of our study is the lack of follow-up to know about the late complications and another limitation is small sample size. 


\section{CONCLUSION}

Early laparoscopic appendicectomy during the index admission of patient with an appendiceal mass is a total curative treatment with short hospital stay, less postoperative pain, minimal morbidity and better patient compliance. It is feasible, safe and avoids the need for a second admission.

\section{Abbreviations}

LA- Laparoscopic Appendicectomy.

JNIMS- Jawaharlal Nehru Institute of Medical Sciences.

\section{REFERENCES}

[1] Arnbjornsson E. Management of appendiceal abscess. Curr Surg 1984;41(1):4-9.

[2] Okafor PI, Orakwe JC, Chianakwana GU. Management of appendiceal masses in a peripheral hospital in Nigeria: review of thirty cases. World J Surg 2003;27(7):800-3.

[3] Nitecki S, Assalia A, Schein M. Contemporary management of the appendiceal mass. Br J Surg 1993;80(1):18-20.

[4] Hogan MJ. Appendiceal abscess drainage. Tech Vasc Interv Radiol 2003;6(4):205-14.

[5] Shipsey MR, O'Donnell B. Conservative management of appendix mass in children. Ann R Coll Surg Engl 1985;67(1):23-4.

[6] Sanapathi PSP, Bhattacharaya D, Amori BJ. Early laparoscopic appendectomy for appendiceal mass. Surg Endosc 2002;16(12):1783-5.

[7] Russel RCG, William NS. Vermiform appendix. Short practice of surgery. 24th edn. CRC Press 2004;(2):1203-8.

[8] De U, Ghosh S. Acute appendicectomy for appendicular mass: a study of 87 patients. Ceylon Med J 2002;47(4): 117-8.

[9] Erdogan D, Karaman I, Narci A, et al. Comparison of two methods for the management of appendicular mass in children. Pediatr Surg Int 2005;21(2):81-3.

[10] Garg P, Das BK, Bansal AR, et al. Comparative evaluation of conservative management versus early surgical intervention in appendicular mass: a clinical study. J Indian Med Assoc 1997;95(6):179-80.

[11] Foran B, Berne TV, Rosoff L. Management of appendiceal mass. Arch Surg 1978;113(10):1144-5.

[12] Janik JS, Ein SH, Shandling B, et al. Nonsurgical management of appendiceal mass in late presenting children. J Paediatr Surg 1980;15(4):574-6.

[13] Bagi P, Dueholm S. Nonoperative management of the ultrasonically evaluated appendiceal mass. Surgery 1987;101(5):602-5.

[14] Oliak D, Yamini D, Udani VM, et al. Nonoperative management of perforated appendicitis without periappendiceal mass. J Surg 2000;179(3):177-81.

[15] Jordan JS, Kovalcik PJ, Schwab CW. Appendicitis with a palpable mass. Ann Surg 1981;193(2):227-9.

[16] Gilchrist BF, Lobe TE, Schropp KP, et al. Is there a role for laparoscopic appendectomy in pediatric surgery? J Pediatr Surg 1992;27(2):209-14.

[17] Pearl RH, Hale DA, Molloy $M$, et al. Pediatric appendectomy. J Pediatr Surg 1995;30(2):173-81.
[18] Semm K. Endoscopic appendectomy. Endoscopy 1983;15(2):59-64.

[19] Attwood SE, Hill AD, Murphy PG. A prospective randomized trial of laparoscopic versus open appendectomy. Surgery 1992;112(3):497-501.

[20] Kum CK, Ngoi SS, Goh PMY, et al. Randomised controlled trial comparing laparoscopic and open appendectomy. Br J Surg 1993;80(12):1599-600.

[21] Thomas DR. Conservative management of the appendix mass. Surgery 1973;73(5):677-80.

[22] Mosegaard A, Nielsen OS. Interval appendectomy. A retrospective study. Acta Chir Scand 1979;145(2): 109-11.

[23] Surana R, Puri P. Appendiceal mass in children. Pediatr Surg Int 1995;10(2-3):79-81.

[24] Horwitz JR, Custer MD, May BH, et al. Should laparoscopic appendectomy be avoided for complicated appendicitis in children? J Pediatr Surg 1997;32(11):1601-3.

[25] Paik PS, Towson JA, Anthone GJ, et al. Intra-abdominal abscesses following laparoscopic and open appendectomies. J Gastrointest Surg 1997;1(2):18893.

[26] Frazee RC, Bohannon WT. Laparoscopic appendectomy for complicated appendicitis. Arch Surg 1996;131(5):509-12.

[27] Valla JS, Steyaert H, Alain LJ. Management of appendiceal peritonitis in children: traditional surgery vs. laparoscopy. Retrospective comparative study of pediatric video surgery group. Int J Pediatr Surg Sci 1996;10:13-6.

[28] Richards KF, Fisher KS, Flores JH, et al. Laparoscopic appendectomy: comparison with open appendectomy in 720 cases. Surg Laparosc Endosc 1996;6:205-9.

[29] Chin CY, Shil C, Chun YC. Laparoscopic appendectomy for ruptured appendicitis. Surg Laparosc Endosc 1999;3:271-5.

[30] Tirabassi MV, Tashjian DB, Moriarty KP, et al. Perforated appendicitis: is laparoscopy safe? JSLS 2004;8(2):147-9.

[31] Maguerditchian AN, Prasil P, Cloutier R, et al Laparoscopic appendectomy in children: a favourable alternative in simple and complicated appendicitis. J Peditar Surg 2002;37(5):695-8.

[32] Paya K, Raunofer U, Rehbandi W, et al. Perforating appendicitis. An indication for laparoscopy? Surg Endosc 2000;14(2):182-4.

[33] Puri P, Boyd E, Guiney EJ, et al. Appendix mass in the very young child. J Pediatr Surg 1981;16(1):55-7.

[34] Vakilli C. Operative treatment of appendix mass. Am J Surg 1976;131(3):312-4.

[35] Lintula H, Kokki H, Vanamo K. Single-blind randomised clinical trial of laparoscopic versus open appendicectomy in children. Br J Surg 2001;88(4): 510-14.

[36] Rai R, Chui CH, Sai Prasad TR, et al. Perforated appendicitis in children: benefits of early laparoscopic surgery. Ann Acad Med Singapore 2007;36(4):277-80.

[37] Yagmurulu A, Vernon A, Barnhart DC, et al. Laparoscopic appendectomy for perforated appendicitis: a comparison with open appendectomy. Surg Endosc 2006;20(7):1051-4. 
[38] Prasad TR, Chui CH, Jacobsen AS. Pediatric laparoscopic appendectomy: safe and effective for all stages of appendicitis and concurrent lesions. J Soc Laparoendoscop Surg 2005;9:S1-77.

[39] Krisher SL, Browne A, Dibbins A, et al. Intra-abdominal abscess after laparoscopic appendectomy for perforated appendicitis. Arch Surg 2001;136(4):43841.
[40] Hoehne F, Ozaeta M, Sherman B, et al. Laparoscopic versus open appendectomy: is the postoperative complication rate different? Am Surg 2005;71(10):813-5. 